\title{
Internal sphincter and haemorrhoids: a pathological study
}

\author{
M. T. HAQQANI ${ }^{1}$ AND B. D. HANCOCK ${ }^{2}$ \\ From the Departments of Pathology and Surgery, University Hospital of South Manchester, UK
}

SUMMARY Histological examination of the lower margin of the internal sphincter has demonstrateकूक an increased amount of fibrous tissue in patients with haemorrhoids compared with controls. This. finding may be of relevance to the treatment of haemorrhoids by maximal anal dilatation.

Interest in the internal sphincter in patients with haemorrhoids has been stimulated by the observation that maximal anal dilatation will relieve symptoms. It seems possible that there is a degree of stenosis in the anal canal which is relieved by dilatation. Recent studies (Hancock and Smith, 1975; Hancock, 1977) have demonstrated a motor abnormality of the sphincter which was abolished by dilatation, but this was not present in every case so there may be other factors that produce a stenosis. Lord (1969), who popularised the dilatation treatment, suggested that there was a pecten band consisting of fibrous tissue in the anal submucosa that may be a primary cause of haemorrhoids.

Since the first detailed description of the pecten band (Miles, 1919) its existence has been disputed and it is now generally accepted as a result of studies at operation that the pecten band is in fact the internal sphincter.

Because there have been no pathological studies of the internal sphincter in patients with haemorrhoids, we examined biopsies of the internal anal sphincter from presumed normal subjects and patients with haemorrhoids.

\section{Material and methods}

Specimens of internal sphincter were taken from 14 patients ( 11 males, 3 females) during the operation of haemorrhoidectomy. A small piece, about $3 \mathrm{~mm}^{3}$, was removed from the lower left lateral

Present addresses:

'Department of Pathology, Walton Hospital, Liverpool, L9 1AE

${ }^{2}$ Department of Surgery, Wythenshawe Hospital, South Moor Road, Manchester, M23 9LT

Received for publication 19 September 1977 margin of the sphincter. Only large vascular haem-o orrhoids were included in the study.

A similar sized sample was taken in the same way from 'normal' internal sphincter obtained from $25^{\mathrm{m}}$ postmortem subjects ( 20 males, 5 females).

The specimens were stained by haematoxylin and eosin, van Gieson, and Masson trichrome techniquesoo and were classified into one of three grades according to the amount of fibrous tissue associated with theo smooth muscle as follows:

Grade I: Fibrous tissue either absent or present aso thin strands running parallel to the muscle fibres (Fig. 1).

Grade II: Fibrous septa abundant and more con-ō spicuous, occupying the entire interstitial spaces (Fig. 2).

Grade III: Dense fibrous tissue in two planes, running parallel to and intersecting groups of muscles fibres (Fig. 3).

The mean age of the patients was 50 years and 3 . all had large prolapsing haemorrhoids. In 10 patients a preoperative anal pressure profile was measured३ (Hancock, 1976). The mean age of the controls waso 62.5 years and it was not known if any of these subjects had suffered with haemorrhoids duringo life.

Results

Distribution of fibrous tissue

Grade I Grade II Grade III

\begin{tabular}{lccc}
\hline $\begin{array}{l}\text { Controls }(\mathrm{n}=25) \\
\begin{array}{l}\text { Haemorrhoids } \\
(\mathrm{n}=14)\end{array}\end{array}$ & 18 & 5 & 2 \\
\hline
\end{tabular}

$\chi^{2}=14.6 \mathrm{P}<0.001$ 


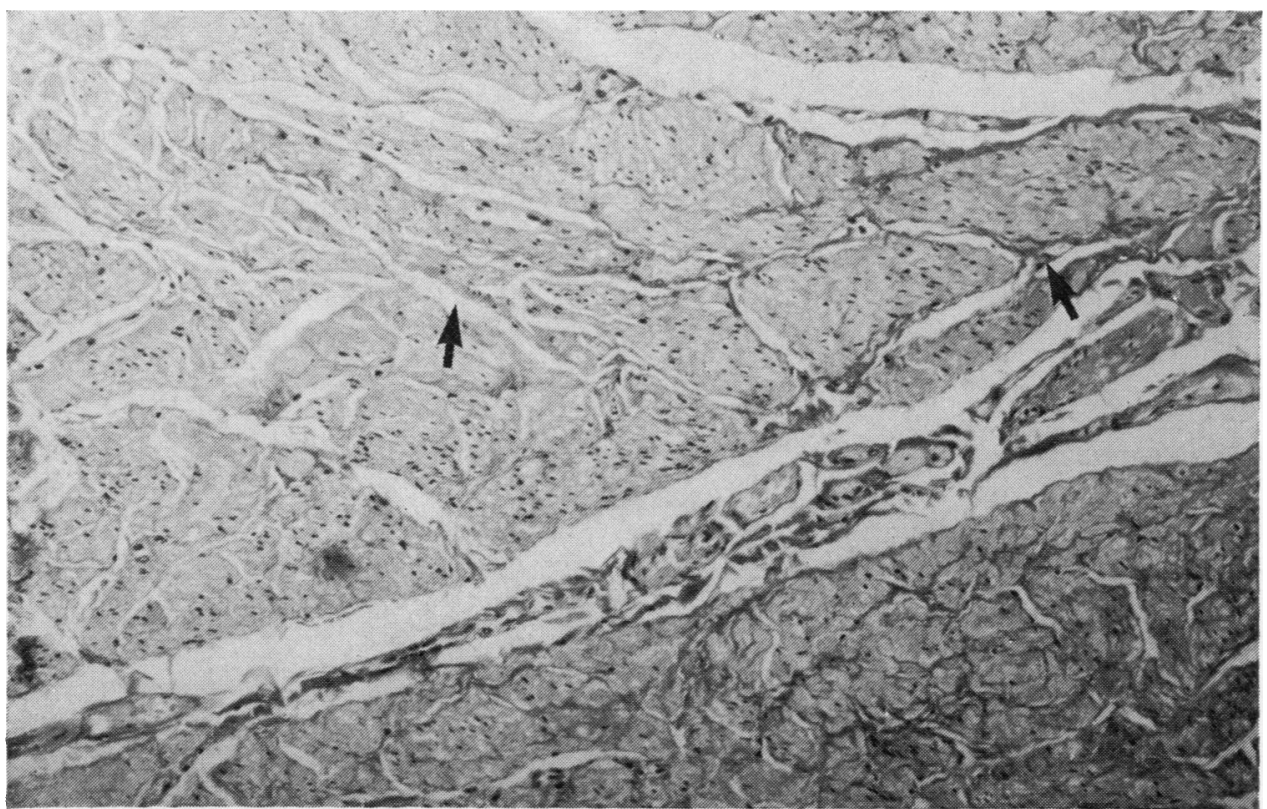

Fig. 1 Empty interstitial spaces or thin strands of fibrous tissue. (van Gieson $\times 55$ )

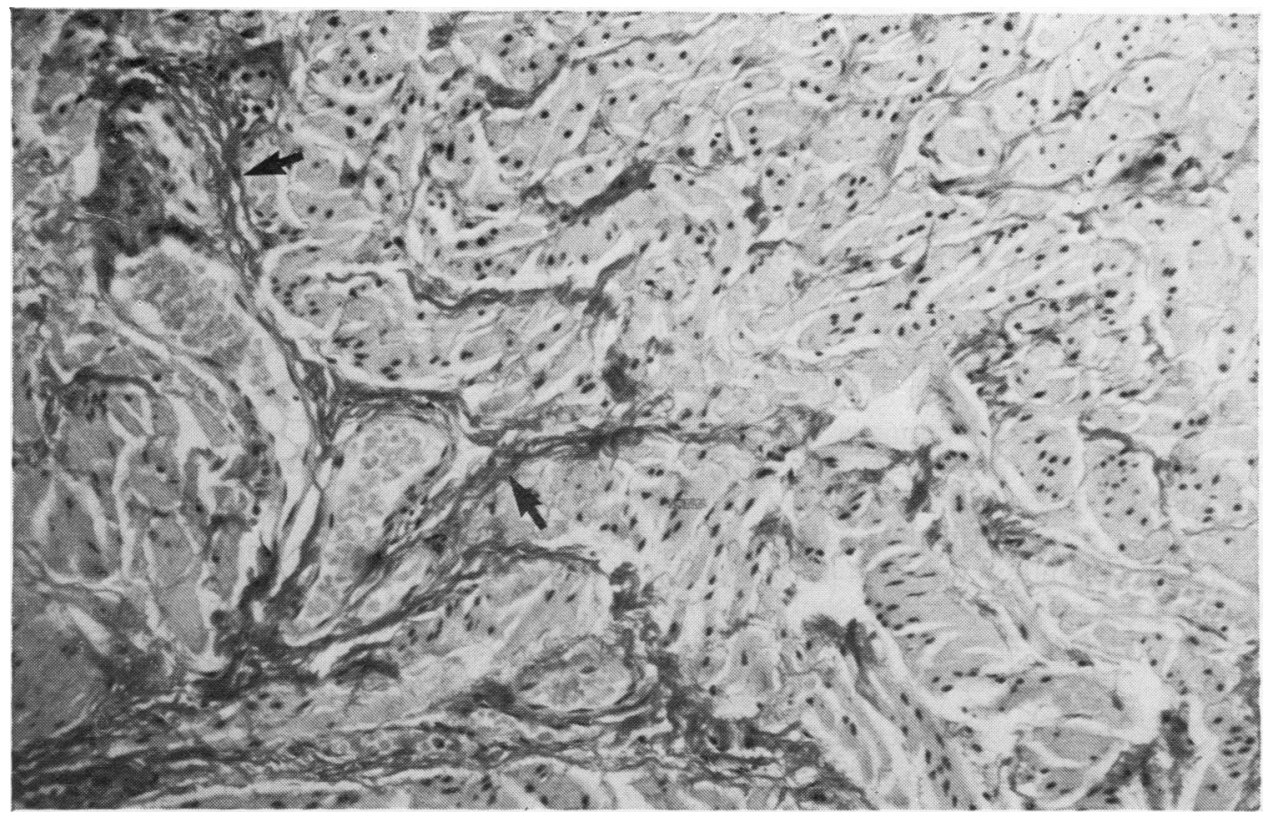

Fig. 2 Abundant fibrous tissue encircling groups of muscle fibres. (van Gieson $\times 148)$ 


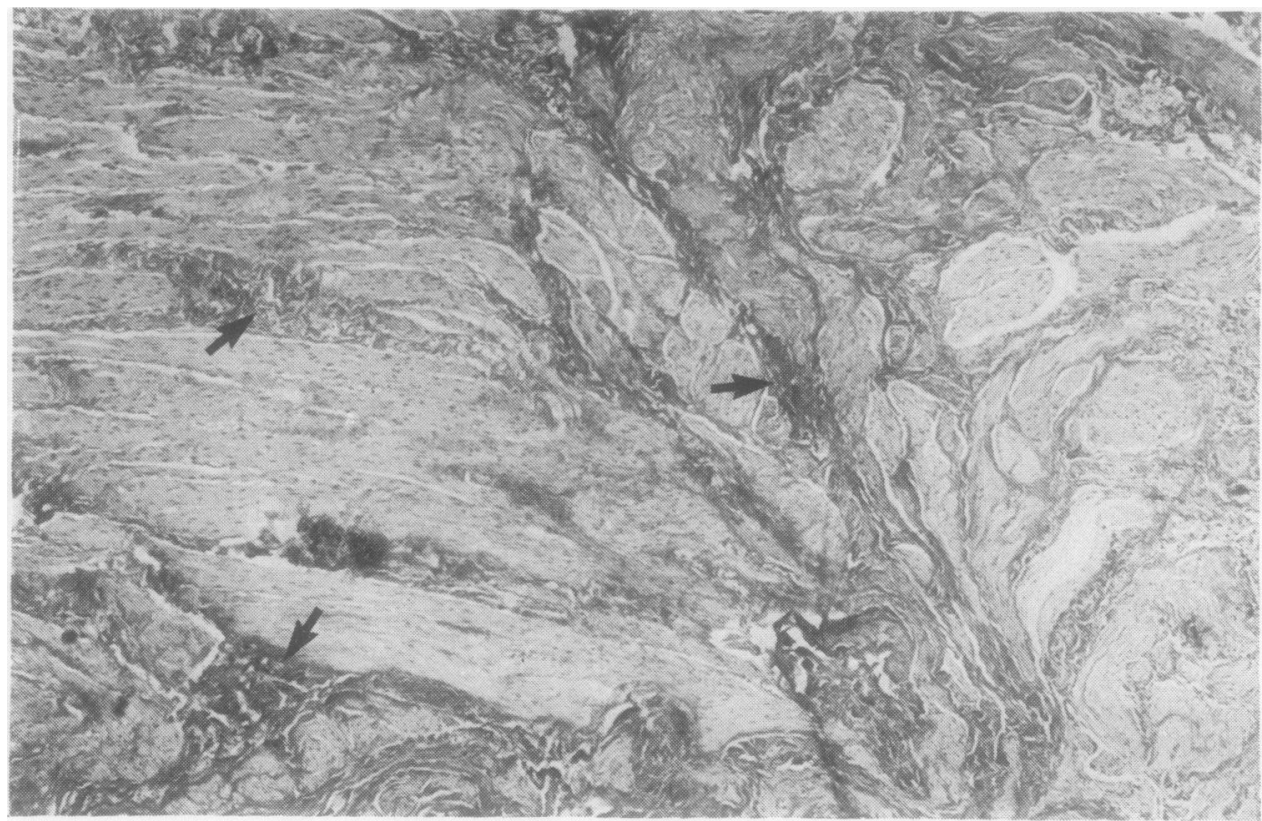

Fig. 3 Dense widespread fibrous tissue in places replacing entire muscle bundles. (van Gieson $\times 55$ )

There was no apparent association between the amount of fibrous tissue and the size or duration of haemorrhoids nor with sphincter activity as estimated by measurement of the preoperative anal pressure.

\section{Discussion}

There appears to be an increased amount of fibrous tissue in the internal sphincter of some patients with haemorrhoids. This is unlikely to be due to an ageing process because the mean age of the controls was greater than that of the patients with haemorrhoids. A possible cause of fibrosis is longstanding vascular congestion, or it could be as a result of repeated traction on the mucosal suspensory ligament which passes as fibromuscular bundles through the internal sphincter.

It might be thought that disruption of fibrous tissue by anal sphincter stretching would lead to increased fibrous tissue formation but the longer term studies after dilatation do not suggest that this happens (Hancock, 1977), so the motor abnormality of the sphincter may be the more important cause of stenosis in some patients with haemor-s rhoids. This finding of increased fibrous tissue in the internal sphincter, however, does lend support to the idea of treating some patients by dilatation.

We thank all consultant surgeons for allowing us to study many of their patients, and the technicians of the histopathology laboratory of the University. Hospital of South Manchester for their help ando co-operation.

\section{References}

Hancock, B. D. (1976). Measurement of anal pressureo and mobility. Gut, 17, 645-651.

Hancock, B. D. (1977). Internal sphincter and the natureo of haemorrhoids. Gut, 18, 651-655.

Hancock, B. D., and Smith, K. (1975). The internaf sphincter and Lord's procedure for haemorrhoids. British Journal of Surgery, 62, 833-836.

Lord, P. H. (1969). A day-case procedure for the cure of third-degree haemorrhoids. British Journal of Surgery 56, 747-749.

Miles, W. E. (1919). Observations upon internal piles. Surgery, Gynaecology and Obstetrics, 29, 497-506. 